\section{An Empirical Protocol for Indirect Measurement of Leaf Area Index in Grape (Vitis vinifera $\mathbf{L}$.)}

\author{
David A. Grantz'and Larry E. Williams ${ }^{2}$ \\ Kearney Agricultural Center, 9240 South Riverbend Avenue, Parlier, \\ CA 93648
}

Additional index words. canopy structure, light interception, gap fraction, plant canopy analyzer

\begin{abstract}
Leaf area development and canopy structure are important characteristics affecting yield and fruit quality of grapevines. Trellising systems and wide row spacing are common viticultural practices that violate key assumptions of currently available indirect methods of leaf area determination. We have developed a protocol for using a commercially available instrument to determine leaf area index (LAI) indirectly in a trellised vineyard. From knowledge of plant spacing, leaf area per vine can be calculated as required. A derived calibration equation resulted in a near $1: 1$ relationship $(y=0.00+1.00$ $X ; r^{2}=0.998$ ) between actual and indirectly determined LAI over a range of LAI induced by irrigation treatments. The protocol involved covering $75 \%$ of the sensor with a manufacturer-supplied field of view delimiter and masking data from the outer three (of five) concentric radiation sensors. The protocol could form the basis for a general measurement technique, but may require local calibration.
\end{abstract}

Leaf area index (LAI; ratio of projected leaf area to ground area) is an important indicator of an annual crop's development, light

Received for publication 13 July 1992. Approved for publication $12 \mathrm{Feb}$. 1993. The cost of publishing this paper was defrayed in part by the payment of page charges. Under postal regulations, this paper therefore must be hereby marked advertisement solely to indicate this fact.

'To whom reprint requests should be addressed. Dept. of Botany and Plant Sciences and Statewide Air Pollution Research Center, Univ. of California, Riverside.

${ }^{2}$ Dept. of Viticulture and Enology, Univ. of California, Davis. interception, water use, productivity, and pollutant deposition; however, LAI is rarely used in viticultural experimentation. Instead, total leaf area per vine (Williams, 1987), canopy surface area per covered ground area (Mullins et al., 1992; Williams et al., 1987), and canopy leaf layer count (Smart, 1985) are used to characterize a vine's canopy development and its light interception. These methods predominate, because direct solar radiation intercepted by leaves on the vine exterior accounts for $\approx 70 \%$ of the carbon fixed by a fully developed vine (Smart, 1974). The above measures also determine a vine's microclimate, which affects fruit quality (Smart, 1985) and incidence of disease (Gubler et al., 1987). They can be related to LAI.

Under many conditions, LAI determination may be the most labor-intensive aspect of a field study (Marshall, 1968), particularly when LAI is determined from destructive harvests. In many cases, i.e., forests, experiments with many plots, and protocols that do not allow biomass removal, destructive LAI measurements are not possible. Many methods have been devised to reduce the dependence of LAI determinations on destructive harvests (Welles, 1990). The point quadrat method involves inserting metal probes through the canopy and counting contacts with individual leaves (Caldwell et al., 1983; Warren Wilson and Reeve, 1959). Similar methods use radiation sensors to determine direct or diffuse radiation interception by individual leaves (Chen and Black, 1991; Lang et al., 1985; Norman and Campbell, 1989; Perry et al., 1988; Walker et al., 1988). Analysis of hemispherical photographs (Anderson, 197 1; Bonhomme and Chartier, 1972) provides similar information. These methods determine the proportion of gaps between foliage elements throughout the canopy and calculate LAI through inversion of a mathematical model (e.g., Lang et al., 1985; Norman andCampbell, 1989; Warren Wilson and Reeve, 1959). Large systematic errors in calculated LAI arise if the canopy does not conform to the mathematical models' assumptions. Row crops, and trellised vineyards in particular, generally violate required assumptions of random and uniform distribution of individual leaves (Lang et al., 1985).

Several commercial instruments for indirectly measuring LAI are available. We have evaluated the Plant Canopy Analyzer (PCA) (model LAI-2000; LI-COR, Lincoln, Neb.), which uses a series of five concentric radiation sensors to determine penetration of diffuse radiation and displays LAI and leaf angular 
distribution-a canopy structural attribute also related to radiation penetration. Spatial sampling is achieved by manually traversing the sensor beneath the canopy. The theory of operation of the PCA has been evaluated in detail (Chason et al., 1991; LI-COR, 1991; Welles and Norman, 1991).

Performance of the PCA under experimental conditions has been mixed. Determining the area of randomly arranged, dark objects was accurate and reproducible, as was performance in an actual crop canopy (Welles and Norman, 199 1). In other cases, the PCA's performance was less satisfactory, even in forests with no imposed row structure (Chason et al., 1991), unless nonstandard protocols were adopted. In a coniferous forest and in a row-cropped broadleaf orchard (Martens et al., 1993), the PCA provided lower LAI estimates than direct and other indirect methods. Our results in field-grown grapevines in the San Joaquin Valley of California also resulted in very low estimates of LAI when the PCA was used in its standard mode (Grantz, 1992). The present study was designed to develop a protocol, including any necessary mathematical transformations, to enable routine use of the LAI-2000 for accurate leaf area determination in grapevines. An analogous protocol has been developed for cotton (Gossypium barbadense L.) (Grantz, 1992; Grantz et al., 1993).

Measurements were obtained in a 5-yearold 'Thompson Seedless' vineyard at the Univ. of California Kearney Agricultural Center, near Fresno. The vines were head-trained and cane-pruned, and rows were oriented eastwest. The trellis system consisted of two wires $0.6 \mathrm{~m}$ apart and $1.8 \mathrm{~m}$ above the soil surface. Vine and row spacings were 2.1 and $3.3 \mathrm{~m}$, respectively. Vines were drip-irrigated with $20 \%, 60 \%, 100 \%$, or $140 \%$ of full vineyard evapotranspiration (ET), determined with a weighing lysimeter (Phene et al., 1991 ). Vines growing within the lysimeter received full replacement irrigation. Vineyard ET from budbreak until the measurement date was $\approx 600$ $\mathrm{mm}$. The vines and irrigation treatments that we used represented two blocks of a larger irrigation study. Two replicate plots were sampled for each irrigation level, except that only one block was sampled at $140 \%$ of ET.

PCA measurements were obtained on 12 Aug. 1991 near sunset ( 1900-2030 HR Pacific Daylight Time), with the instrument operator facing east. A field of view (FOV) delimiter ( $25 \%$ open facing away from the operator) supplied by the manufacturer was used for all observations. Each sample consisted of four observations evenly spaced across the row: the center of the planted row (mid-row), onefourth, midway, and three-fourths of the distance to the adjacent planted row. The midrow of the adjacent row was not sampled. Individual samples were replicated five times at 4-m intervals as the operator advanced east, alternating the plant row to be sampled for the mid-row measurement. Five such determinations were made in each plot. All observations, including those over the furrows, were made at the elevation of the ridge in the planted row.
The five samples per plot $(\mathrm{n}=20)$ were collected as a single determination of LAL No spatial heterogeneity in LAI was detected; thus, all five determinations were pooled by removing the file delimiters inserted by the PCA software and analyzing the readings as a single estimate of LAI (mean $\pm \mathrm{SE}$ ), using the optional calculation mode "FCS" of the LICOR 1000-90 software. The three outermost rings, radiation sensors 3,4 , and 5 , were not considered during LAI calculations using the software's Mask feature. The PCA measures gap fraction, responding to the silhouette of all plant elements, including trunk and branches, trellis stakes, drip irrigation tubing, fruits, etc. We made no corrections for this substantial overestimation of LAI.

LAI was determined destructively on one entire vine per irrigation treatment per block on 13 and 14 Aug. 1991. Total leaf area was measured by detaching all leaves from each vine and measuring total one-sided area with a LI-COR leaf area meter (LI3100). A single LAI value per plot was obtained from the single vine by dividing the measured leaf area by the total ground area allotted to each vine within the vineyard $\left(6.9 \mathrm{~m}^{2} / \mathrm{vine}\right)$.

The conventional PCA protocol results were disappointing (Fig. 1). When LAI was determined using all five concentric sensors of the PCA, apparent LAI was consistently lower than actual LAI (determined destructively). The relationship was curvilinear, with PCA values typically about half of the actual values
(Fig. 1), despite several precautions. All measurements were made with the $25 \%$ FOV delimiter in place (LI-COR, 1991; Welles and Norman, 1991), and all measurements were averages of the four distinct canopy environments across the row. These errors likely result from the view of the open areas between the rows, which could dominate the FOV of the outermost sensors during all measurements. By masking the outer, more horizontal sensor rings, measurements at each row position are as specific for that position as possible.

Other PCA users have advocated deleting data from the outer (one or more) sensor rings. Errors in vertically oriented canopies, such as small grains, have been attributed to light scattering, consequently overestimating light gaps and underestimating LAI. LI-COR (1991) suggests correction by masking sensor 5 data. The PCA is designed with optical filters to remove radiation with wavelengths $>490 \mathrm{~nm}$, at which scattering is more pronounced, to overcome this effect. Erroneous determinations of LAI in a clumped (i.e., not randomly distributed) Douglas fir $[P$ seudotsuga menziesii (Mirbel) France] canopy with horizontal branches (Chen and Black, 1991) were attributed to large enhancement of diffuse light, particularly at large incidence angles (i.e., sensor 5), by scattering blue diffuse radiation. In a mixed-age deciduous forest (Chason et al., 1991), sensor 5 consistently overestimated gap fraction and underestimated LAI, and most accurate data were obtained by

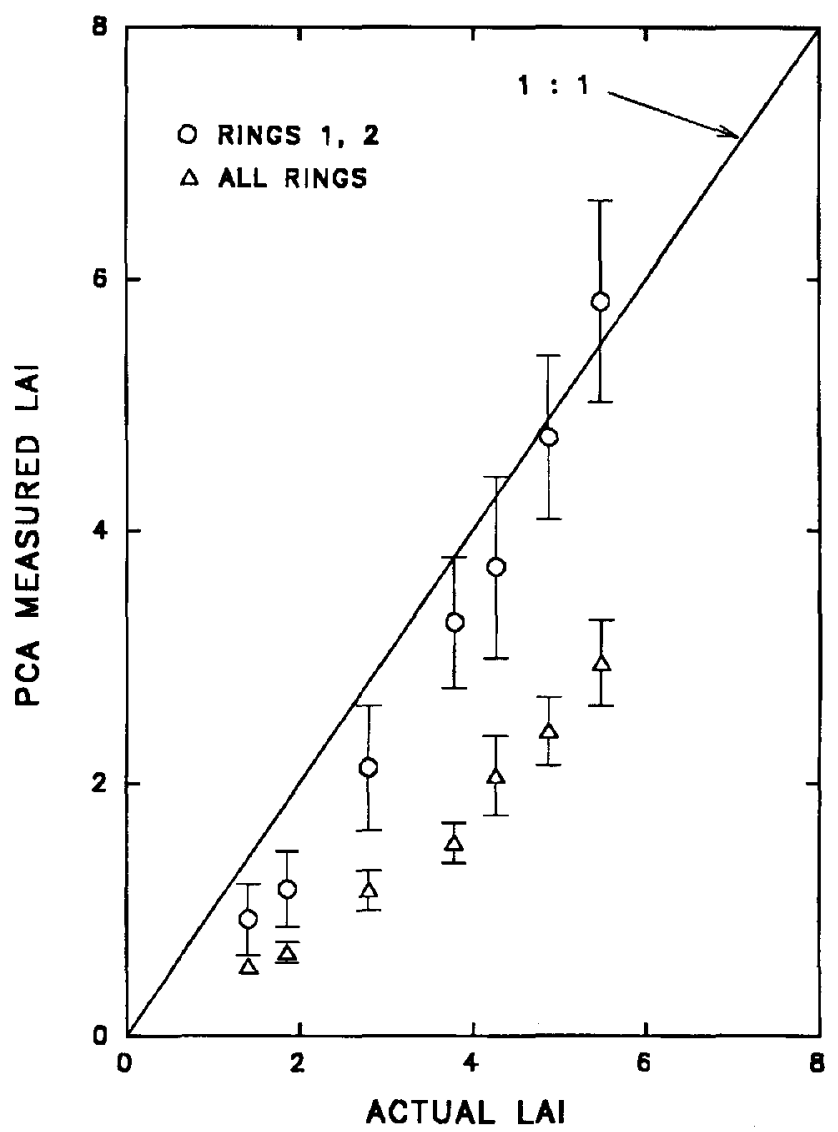

Fig. 1. Relationship between leaf area index (LAI) determined indirectly with the Plant Canopy Analyzer (PCA)andactualLAIdeterminedfromdestructiveharvests.Trianglescalculated usingall five radiation sensors. Circles calculated using the central two sensor rings. The solid line represents the 1:1 relationship. Bars indicate SE and $\mathrm{n}=20$ for each point. 
masking the outer three rings. In this case, the problem appeared to be increasingly uniform foliage distribution as path length increased obliquely under the forest canopy, particularly with the more horizontally oriented sensors. Enhanced scattered radiation at high zenith angles could also have been a factor.

Our PCA measurements also more accurately reflected actual LAI when data from sensors 3- 5 were masked and only data from sensors 1 and 2 were used for calculations (Fig. 1). These data lay below the actual values of LAI until LAI reached values of $\approx 5$. Nevertheless, the discrepancy between indirect and actual LAI was $>20 \%$ in several cases, which is unacceptable. A regression analysis of this relationship indicated a highly significant, though curvilinear, relationship $\left(r^{2}=0.997 ; \mathrm{n}\right.$ $=7$ ) of the form PCA $=0.64+0.17 \mathrm{LAI}^{2}$, in which LAI is actual LAI, and PCA is obtained using the nonstandard measurement protocol. This regression equation can then be inverted and applied as a calibration curve. This results in a highly significant linear relationship $\left(r^{2}=\right.$ $0.998 ; \mathrm{n}=7$ ) of the form LAI $=0.00+1.00$ PCA', in which PCA' is the value obtained using the nonstandard protocol described above and transformed using the calibration equation. This results in a relationship between PCA-measured and actual LAI values that is experimentally indistinguishable in slope and intercept from the desired 1:1 line (Fig. 2).

Several theoretical assumptions, in addition to those regarding canopy geometry discussed above, underlie the measurement of
LAI using the PCA. These include a defined minimum distance between the sensor head and the nearest foliage element (LI-COR, 1991; Welles and Norman, 1991), a uniformly diffuse-lighted sky, and no direct beam radiation incident on the experimented area. These assumptions and those regarding canopy geometry are commonly violated under experimental conditions, particularly in row-crop canopies. Yet, the desirability of LAI measurements persists, leading to a search for acceptable, if somewhat empirical, measurement methods (Chason et al., 1991; Grantz, 1992; Welles and Norman, 1991).

An empirically derived measurement and calculation protocol, including a potentially site-specific calibration curve, may represent the most feasible approach currently available to determine LAI nondestructively. A method such as that described here may allow accurate, indirect LAI determinations in vineyards and other row crops (e.g., cotton; Grantz, 1992; Grantz et al., 1993) in which other methods, including use of the PCA according to the manufacturer's guidelines, have proven time-consuming or otherwise unsatisfactory. This rapid method of determining LAI may provide useful measures of grapevine canopy development that could be correlated with more conventional viticultural measures of canopy density and resulting fruit quality.

\section{Literature Cited}

Anderson,M.C.1971.Radiationandcropstructure,p.412466. In: Z. Sestak, J. Catsky, and P.G. Jarvis (eds.).

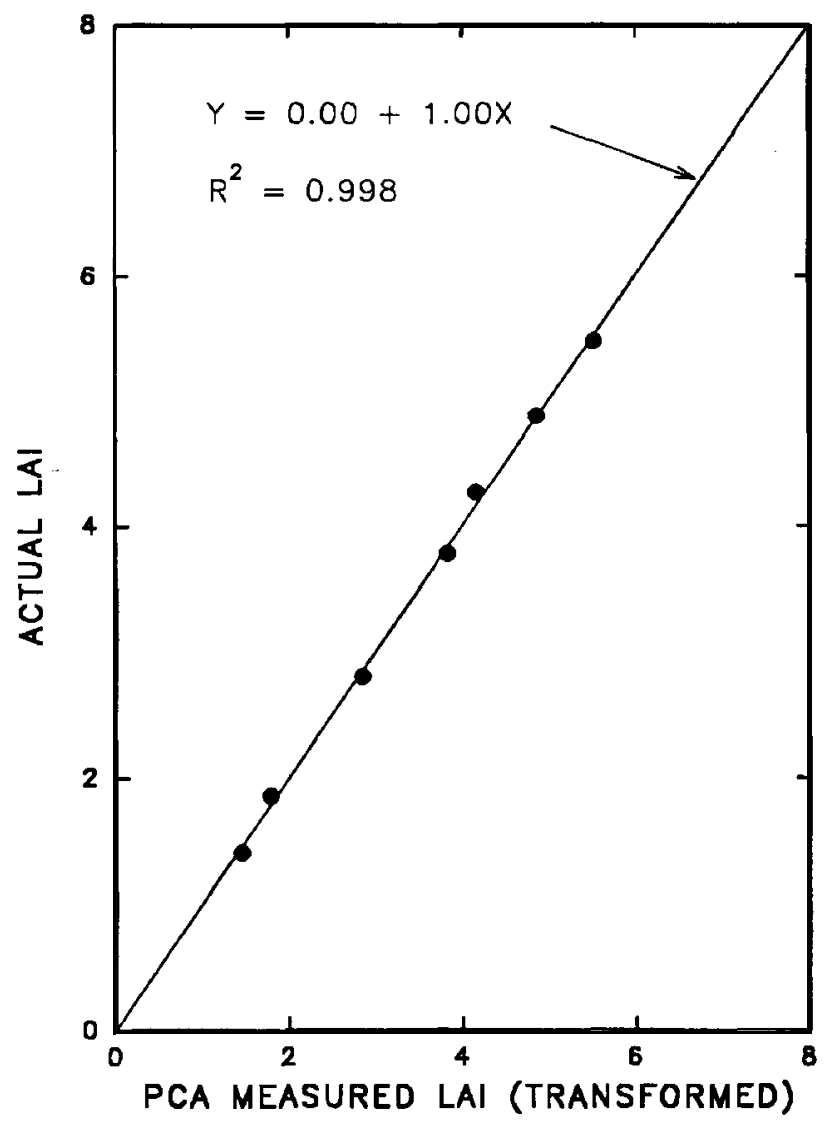

Fig. 2. Relationship between actual leaf area index (LAI) measured from destructive harvests and LAI determined indirectly with the Plant Canopy Analyzer (PCA) using sensor rings 1 and 2 and the empirical calibration equation.
Plant photosynthetic production: Manual of methods, W. Junk, The Hague, The Netherlands.

Bonhomme, R. and P. Chartier. 1972. The interpretation and automatic measurement of hemispherical photographs to obtain sunlit foliage area and gap frequency. Israel J. Agr. Res. 22:53-61.

Caldwell, M, M., G.W. Harris, and R.S. Dzurec. 1983. A fiber optic point quadrant system for improved accuracy in vegetation sampling. Oecologia 59:417-418.

Chason, J.W., D.D. Baldocchi, and MA. Huston. 1991. A comparison of direct and indirect methods for estimating forest canopy leaf area. Agr. For. Meteorol. 57:107128.

Chen, J.M. and T.A. Black. 1991. Measuring leaf area index of plant canopies with branch architecture. Agr. For. Meteorol,.57:1-12.

Grantz, D.A. 1992. Biophysical measurements to support CODE-91, the California Ozone Deposition Experiment. Final Rpt. San Joaquin Valley Air Pollution Study Agency, California Air Resources Board, Sacramento, Contract 91-1 1.

Grantz, D.A., X.J. Zhang, P.D. Metheney, and D.W. Grimes 1993. Indirect measurement of leaf area index in Pima cotton (Gossypium barbadense L.) using a commercial gap inversion method, Agr. For. Meteorol. (In press.)

Gubler, W. D., J.J. Marois, A.M. Bledsoe, and L. Bettiga. 1987. Control of botrytis bunch rot of grape with canopy management. Plant Dis. 71:599-601.

Lang, A.R.G., Y. Xiang, and J.M. Norman. 1985. Crop structure and the penetration of direct sunlight. Agr. For, Meteorol. 35:83-101.

LI-COR. 1991. LAI-2000 plant canopy analyzer operating manual. LI-COR, Lincoln, Neb.

Marshall, J.K. 1968. Methods for leaf area measurement of large and small leaf samples. Photosynthetica 2:41-47.

Martens, S.N., S.L. Ustin, and R.A. Rousseau. 1993. Estimation of tree canopy leaf area index by gap fraction analysis. For. Ecol. Mgt. (In press.)

Mullins, M.G., A. Bouquet, and L.E. Williams. 1992 Biology of the grapevine. Cambridge University Press, Cambridge, U.K.

Norman, J.M. and G.S. Campbell. 1989. Canopy structure, p. 300-325. In R.W. Pearcy, J. Ehleringer, H.A. Mooney, and P.W. Rundel (eds.). Plant physiological ecology Field methods and instrumentation. Chapman and Hall, New York.

Perry, S.G., A.B. Fraser, D.W. Thomson, and J.M. Norman. 1988. Indirect sensing of plant canopy structure with simple radiation measurements. Agr. For. Meteorol. 42:255-278.

Phene, C.J., G.J. Hoffman, T.A. Howell, D.A. Clark, R.M. Mead, R.S. Johnson, and L.E. Williams. 1991. Automated lysimeter for irrigation and drainage control, $\mathrm{p}$. 28-36. In: Lysimeters for evapotranspiration and environmental measurements. Proc. Intl. Symp. on Lysimetry, Honolulu, Hawaii, 23-25 July 1991. Amer. Soc. Civil Eng., New York.

Smart, R.E. 1974. Photosynthesis by grapevine canopies. J. Applied Ecol. 11:997-1006.

Smart, R.E. 1985. Principles of grapevine canopy microclimate manipulation with implications for yield and quality: A review. Amer. J. Enol. Viticult. 36:230-239.

Walker, G. K., R.E. Blackshaw, and J. Dekker. 1988. Leaf area and competition for light between plant species using direct sunlight transmission. Weed Technol. 2:159-165.

Warren Wilson, J. and J.E. Reeve. 1959. Analysis of the spatial distribution of foliage by two-dimensional paint quadrants. New Phytol. 58:92-101.

Welles, J.M. 1990. Some indirect methods of estimating canopy structure. Remote Sensing Rev.5:31-43.

Welles, J.M. and J.M. Norman. 1991. Instrument for indlrect measurement of canopy architecture. Agron. J. 83:818-825.

Williams, L.E. 1987. Growth of 'Thompson Seedless' grapevines: I. Leaf area development and dry weight distribution. J. Amer. Soc. Hort. Sci. 112:325-330.

Williams, L.E., P.J. Biscay, and R.J. Smith. 1987. Effect of interior canopy defoliation on berry composition and potassium distribution in Thompson Seedless grapevines, Amer. J. Enol. Viticult. 38:287-292. 